\title{
Level and change of group-focused enmity in Germany: unconditional and conditional latent growth curve models with four panel waves
}

\author{
Davidov, Eldad ; Thörner, Stefan ; Schmidt, Peter ; Gosen, Stefanie ; Wolf, Carina
}

\begin{abstract}
In this study we investigate and explain the level and change of six elements of group- focused enmity (GFE; see Zick et al. 2008) in Germany between 2002 and 2006: racism, xenophobia, antiSemitism, homophobia, exclusion of homeless people and support for rights of the established. For the data analysis, a representative 4-year panel study of the adult non-immigrant German population collected during the years 2002-2006 is used, and the development of each GFE component is tested by using an unconditional second- order latent growth curve model (LGM) (with full information maximum likelihood, FIML). We find that the level of 5 of the 6 components (racism, xenophobia, anti- Semitism, homophobia, exclusion of homeless people) displays an increase at the beginning of the observed period followed by a decrease. However, the sixth aspect, rights of the established, displays a continuous linear increase over time. The different developmental pattern stands in contrast to Allport's hypothesis (1954) for the strong link between the components and their development over time. We try to explain this different developmental pattern by several sociodemographic characteristics. This is performed by using a conditional second-order latent growth curve model.
\end{abstract}

DOI: https://doi.org/10.1007/s10182-011-0174-1

Posted at the Zurich Open Repository and Archive, University of Zurich

ZORA URL: https://doi.org/10.5167/uzh-55138

Journal Article

Accepted Version

Originally published at:

Davidov, Eldad; Thörner, Stefan; Schmidt, Peter; Gosen, Stefanie; Wolf, Carina (2011). Level and change of group-focused enmity in Germany: unconditional and conditional latent growth curve models with four panel waves. AStA Advances in Statistical Analysis, 95(4):481-500.

DOI: https://doi.org/10.1007/s10182-011-0174-1 


\title{
Level and change of group-focused enmity in Germany: unconditional and conditional latent growth curve models with four panel
} waves

\author{
Eldad Davidov ${ }^{1}$, Stefan Thörner ${ }^{2}$, Peter Schmidt ${ }^{3}$, Stefanie Gosen ${ }^{2}$, \\ Carina Wolf ${ }^{4}$ \\ ${ }^{1}$ University of Zurich, Zurich, Switzerland $-{ }^{2}$ University of Gießen, Gießen, Germany $-{ }^{3}$ State \\ University Higher School of Economics, Moscow, Russia $-{ }^{4}$ University of Bielefeld, Bielefeld, \\ Germany
}

This is a pre-copy-editing, author-produced PDF of an article accepted for publication in the journal AStA Advances in Statistical Analysis 2011 95(4):481-500 following peer review. It was first published online in this journal on October 18, 2011. The definitive publisher-authenticated version is available online at:

http://www . springerlink. com/content/22883437h22516v0/

or under

doi:10.1007/s10182-011-0174-1 


\title{
Level and Change of Group-Focused Enmity in Germany:
}

\section{Unconditional and Conditional Latent Growth Curve Models with}

\section{Four Panel Waves}

\author{
$\underline{\text { Abstract }}$ \\ In this study we investigate and explain the level and change of six elements of group- \\ focused enmity (GFE; see Zick et al. 2008) in Germany between 2002 and 2006: racism, \\ xenophobia, anti-Semitism, homophobia, exclusion of homeless people and support for \\ rights of the established. For the data analysis, a representative 4-year panel study of the \\ adult non-immigrant German population collected during the years 2002-2006 is used, \\ and the development of each GFE component is tested by using an unconditional second- \\ order latent growth curve model (LGM) (with full information maximum likelihood, \\ FIML). We find that the level of 5 of the 6 components (racism, xenophobia, anti- \\ Semitism, homophobia, exclusion of homeless people) displays an increase at the \\ beginning of the observed period followed by a decrease. However, the sixth aspect, \\ rights of the established, displays a continuous linear increase over time. The different \\ developmental pattern stands in contrast to Allport's hypothesis (1954) for the strong link \\ between the components and their development over time. We try to explain this different \\ developmental pattern by several sociodemographic characteristics. This is performed by \\ using a conditional second-order latent growth curve model.
}

Key words: group-focused enmity; syndrome; prejudice; conditional and unconditional latent growth curve modeling; panel data 


\section{Introduction}

The issue of prejudice toward minorities and its relation to discrimination has been studied early on. In recent years it has drawn increasing attention in the European legal system. The European Union has been active in the fight against discrimination and in promoting equal opportunities, and with the Amsterdam Treaty in 1997 (European Parliament) came new, far-reaching powers to take actions to combat discrimination based on gender, racial or ethnic origin, religion or belief, disability, age or sexual orientation (Heitmeyer 2003; Marsh and Sahin-Dikmen 2003). This has resulted in an increasing study of prejudicial expressions in recent years. Building on Allport's (1954) and Adorno, Frenkel-Brunswik, Levinson and Sanford's (1950) generalized prejudice theory, these studies have found that prejudice against foreigners, people of another race, Jews, homosexuals, Muslims or homeless people can be understood as an expression of one syndrome, group-focused enmity (GFE) (see, e.g., Zick, Wolf, Küpper, Davidov, Schmidt, and Heitmeyer 2008). Whereas this line of work is very important for the understanding of prejudice in modern societies at a specific time point, only a few studies have tried to study the development of group-focused enmity over time. However, such studies are paramount for monitoring societies and better understanding of the development of prejudice and its sources over time (e.g., Datenreport 2008).

The increasing availability of panel data has encouraged the development and utilization of methods to analyze them in recent years. One of the methods seldom used in this field but potentially very useful is latent growth modeling (LGM) which is also known as latent curve analysis (Meredith and Tissak 1990, Bollen and Curran 2006). 
This technique describes individual development in terms of initial levels and developmental trajectories on the group as well as on the individual levels. This method has several advantages over more traditional methods to analyze data over time, which will be exemplified in our empirical study.

In this study we firstly intend to study the development over time of different elements of GFE in Germany in recent years (between 2002 and 2006) using representative panel data. Furthermore, we try to explain its dynamics by social structural variables. Using LGM modeling with multiple indicators, we are in a position to test level and change of the GFE elements and to explain them. The uniqueness of the LGM approach provides us the opportunity not only to study the change of GFE elements in Germany, but also to investigate individual variability around this change and test whether it can also be predicted by social-structural variables such as age, education, political orientation and place of residence.

The paper is structured as follows. We start by providing theoretical background about the generalized prejudice syndrome of group-focused enmity and its elements. Next, we introduce the LGM model and the procedures for a higher order LGM that we apply here. In the next section we describe the data and the variables used, drawn from a representative sample of the adult German population. Subsequently, we display the results. The paper finalizes with a summary of the substantial findings on level and change of prejudice in Germany.

\section{Theoretical Background}




\subsection{Generalized Prejudice: The Concept of Group-focused Enmity and its Empirical Evidence}

Prejudice and discrimination are widespread throughout the world. For several decades now researchers have proposed that prejudices against different target groups are not independent of each other, but are rather closely linked phenomena (e.g., Sumner 1906, Adorno et al. 1950, Allport 1954, LeVine and Campbell 1972). More than half a century ago, Gordon W. Allport noted that "[o]ne of the facts of which we are most certain is that people who reject one out-group will tend to reject other out-groups. If a person is anti-Jewish, he is likely to be anti-Catholic, anti-Negro, anti any out-group" (Allport 1954: 68). In other words, prejudice is understood as a unitary phenomenon by this research group. We build upon these approaches and consider enmity toward different minority groups as being closely related to each other and deriving from a generalized attitude toward outgroups.

Surprisingly few attempts have been made to profoundly examine different elements of the generalized prejudice construct and, for the most part, different prejudices have even been analyzed in separate lines of research. Nevertheless, numerous studies show that different types of prejudice are substantially interrelated, i.e., people with high levels of prejudice against one group tend to have high levels of prejudice against other groups and vice versa.

Just to mention a few of them, in an early study by Kogan (1961), negative attitudes toward elderly people were found to be positively correlated with negative attitudes toward Blacks, ethnic minorities and disabled people. Bierly (1985) presented evidence that people with homophobic attitudes tend to express misogynous attitudes and to 
devaluate Blacks and old people. In addition, Whitley (1999) showed different forms of prejudice (affective, stereotypes, attitudes) to be closely interlinked.

The high correlations between different types of prejudice obtained in past and more recent research support the idea of generalized prejudice (Zick et al. 2008). Besides these inter correlations among different prejudice elements, some studies have presented more profound empirical evidence for generalized prejudice by either developing reliable scales including several prejudices (Guimond, Dambrun, Michinow and Durarte 2003), or by forming a second order factor of several prejudices (Heyder and Schmidt 2003; Ekehammar, Akrami, Gylje and Zakrisson 2004; Bratt 2005). For instance, a highly reliable scale of prejudices against 17 different ethnic out-groups was created by Guimond and his co-workers (2003). In Bratt's (2005) analysis, prejudices against five non-Western immigrant groups were found to load on one underlying second order factor (see Bratt for other possible factorial solutions). Heyder and Schmidt (2003) reveal one second order factor accountable for the lower order factors of anti-Semitism, antiforeigner sentiments and in-group favoritism. Ekehammar et al. (2004) constructed a second order factor out of prejudices against several very heterogeneous out-groups (women, ethnic groups, mentally disabled, homosexuals).

Employing large probability samples of the German population, Zick et al. (2008) also find support for the contention of generalized prejudice. But besides a second order factor of seven different prejudice constructs, their analyses go beyond it by examining the common core of their concept of group-focused enmity syndrome, by testing its stability over time and by analyzing its common causes and consequences. 
These studies investigated the properties and validity of the GFE syndrome as a second order factor. However, the development of GFE and its elements in Germany over time have not been investigated yet. Furthermore, it is still not clear whether all the GFE elements take a similar developmental form and which factors predict the level and change of GFE. In the next sections we will address these questions.

\subsection{Sociodemographic Predictors of Prejudice}

Education is often used as a predictor of prejudice. However, it is not clear in what way it affects prejudice. Kunovich (2004) proposes two views that have been previously reported in the literature. The "education-as-liberator view" (Jackman and Muha 1984) suggests that education decreases prejudice. Social scientists suggest that there is a negative relation between education and prejudice, because education increases norms of democracy of individuals (Hla). By contrast, the "education-as-superficial commitment view" (Jackman and Muha 1984) suggests that any association between education and prejudice is only a result of measurement bias (satisfying the interviewer's expectations) or of a superficial level of support for tolerance (see, e.g., Jackman 1978). According to this view, those with higher education will only exhibit lower levels of prejudice, but in actuality are as prejudiced as other people.

Other sociodemographic variables used in the literature to explain the level of prejudice are age, political orientation and place of residence. Kunovich (2004) finds that age has a positive effect on prejudice with older people displaying higher levels of prejudice $(\mathrm{H} 2 \mathrm{a})$. Political orientation naturally affects prejudice, and individuals with a right-wing political orientation are expected to be more prejudiced than those without 
(H3a). Finally, in the German context, place of residence (i.e., East or West Germany) plays an important role in the explanation of the level and change of prejudice. The two parts of the country have different political and historical climates, and people in the Eastern part of Germany tend to devaluate out-groups, at least foreigners, more strongly (Heyder and Schmidt 2003) (H4a).

Whereas arguments in previous studies lead us to expect sociodemographic variables to exert an effect on the level of the GFE elements, they do not provide us with information as to what effects these variables should have on change of the GFE elements. As we do not have any preceding information, we derive our hypotheses with a similar logic. With respect to education, as education is expected to have a negative effect on prejudice and GFE, it is also expected to have a negative effect on their growth. Thus, with increasing education, prejudice is expected to grow more slowly $(H 1 b)$. As age is expected to have a positive effect on prejudice, it is also expected that older people's prejudice increases more rapidly over time $(H 2 b)$. Similarly, a right-wing political orientation is expected to have a positive effect on the growth of prejudice over time $(H 3 b)$. Finally, not only are people living in East Germany expected to be more prejudiced, but we anticipate that their prejudice increases more quickly over time $(H 4 b)$.

\section{Method}

\subsection{The Latent Growth Curve (LGM) Model}

Latent growth models (LGM) represent a major approach in the analysis of level and change using panel data. They provide information about the individual growth or decline of individuals by estimating an underlying trajectory over time for each individual. Based 
on the work of Tucker (1958) and Rao (1958), they were firstly proposed by McArdle (1986), McArdle and Epstein (1987) and Meredith and Tisak (1990) and further discussed by Bollen and Curran (2006) and Duncan, Duncan and Strycker (2006). The basic idea behind LGM models is that individual development (growth or decline) for a given concept is a function of a latent random intercept and a latent random slope. Whereas the latent intercept represents the average initial position of individuals in the process, the latent slope represents the average development (increase or decrease; or change rate) over time. The LGM function for an observed indicator in the univariate case can be represented as follows:

$$
y_{i t}=\alpha_{i}+\lambda_{t} \beta_{i}+\varepsilon_{i t}
$$

where $y_{i t}$ is the observed indicator for individual $i$ at time point $t$. It is explained by two latent factors, $\alpha_{i}$ and $\beta_{i}$. $\alpha_{i}$ reflects the initial level and represents the latent intercept. $\beta_{i}$ represents the individual latent slope factor and reflects the (linear) rate of change per unit of time. For both $\alpha_{i}$ (the intercept) and $\beta_{i}$ (the slope) a mean and a variance can be estimated. The average intercept indicates the average initial level on the group level, and the average slope indicates the average change in each unit of time on the group level. The variance of the intercept indicates the individual variability around the group parameter of the initial level. The variance of the slope indicates the individual variability around the group parameter of change. In such a way, the process of change of each individual is taken into account in order to form an estimated single underlying trajectory for each person over time. $\varepsilon_{i t}$ represents a random error, and $\lambda_{t}$ specifies the time course. However, one can leave the specification of the process free and estimate it. In this way, contrary to Markov models (Finkel 1995), one can test whether the change process is 
linear or not.The subscript $\mathrm{i}$ indicates that both the latent intercept and the latent slope are allowed to vary across individuals.

This idea can be expressed by the following function specifying group and individual influences:

$$
\begin{aligned}
& \alpha_{i}=\mu_{\alpha}+\zeta_{\alpha i} \\
& \beta_{i}=\mu_{\beta}+\zeta_{\beta i}
\end{aligned}
$$

Both latent factors, $\alpha_{i}$ and $\beta_{i}$, are specified by their means $\left(\mu_{\alpha}\right.$ and $\left.\mu_{\beta}\right)$ and their residuals $\left(\zeta_{\alpha i}\right.$ and $\left.\zeta_{\beta i}\right)$. As long as no additional predictors such as social structural variables are introduced into the model (the so-called 'unconditional LGM'), $\zeta_{\alpha i}$ and $\zeta_{\beta i}$ may be interpreted as the deviations from the group mean of the intercept and the slope factors. Once exogenous variables to predict $\alpha_{i}$ and $\beta_{i}$ are introduced into the model (the so-called 'conditional LGM'), $\zeta_{\alpha i}$ and $\zeta_{\beta i}$ may be interpreted as the part of the deviations from the group mean not accounted for by these exogenous variables.

LGMs can also be modeled for latent constructs instead of single observed indicators (the so-called second order LGMs; see Hancock, Wen-Ling and Lawrence 2001, Bollen and Curran 2006, Duncan et al. 2006, and Schlüter et al. 2006). This approach is an alternative to the common generation of an index, because the use of multiple indicators enables the researcher to control for measurement errors. According to this approach, a latent construct $\eta_{i j}$ for individual i measured at time point $\mathrm{j}$ measured by k indicators $Y_{i j}$ can replace $y_{i t}$ in formula 1 . The corresponding measurement model is

$$
y=\tau+\Lambda \eta+\varepsilon
$$


where $\tau$ represents an intercept, $\Lambda$ a vector of factor loadings and $\varepsilon$ measurement error. To model growth of the latent constructs, we use the generalized model (see Graff and Schmidt 1982, Bollen 1989):

$$
\eta=\alpha+\mathrm{B} \eta+\zeta
$$

In this case, $\alpha$ is a vector of intercepts, which represent the initial level of the process. B is a matrix of second order factor loadings which specifies the hypothesized growth pattern that underlies the $\eta$ constructs. $\zeta$ is a vector of stochastic errors in the first order latent constructs.

Estimation of a process of change using the LGM model can be done using panel data and any SEM software, such as AMOS (Arbuckle 2007, Byrne 2010), EQS (Bentler 1995, Byrne 2006), LISREL (Jöreskog and Sörbom 2001), Mplus (Muthén and Muthén 1998-2010) or OpenMX (Ozaki et. al. 2009). It may be conducted by the full information maximum likelihood (FIML) procedure (Allison 1987, Muthén, Kaplan and Hollis 1987, Bollen 1989, Arbuckle 1996, Enders 2001, Brown 2006) assuming multivariate normality by maximizing

$$
\log L_{i}=K_{i}-\frac{1}{2} \log \left|\sum_{i}\right|-\frac{1}{2}\left(x_{i}-\mu_{i}\right)^{\prime} \sum_{i}^{-1}\left(x_{i}-\mu_{i}\right)
$$

Where $L_{i}$ is the $\log$ likelihood function for individual $i$ that measures the discrepancy between the observed data and parameter estimates with all model variables that are complete for case $i$ (Enders 2001). $\mathrm{K}$ is a constant that depends only on the number of indicators, $\mathrm{x}$ are observed indicators, and $\mu$ and $\Sigma$ are the population mean vector and covariance matrix (Arbuckle 1996). This likelihood function is especially useful in the analysis of panel data with structural equation modeling since it has been shown that it 
deals effectively with missing values (similarly to multiple imputation; see Schafer and Graham 2002; Kleinke et al. in press). The approach uses all the available data during the estimation. When data are missing either completely at random (MCAR) or at random (MAR) and have a multivariate normal distribution, full information maximum likelihood produces parameter estimates, standard errors and test statistics that are consistent and efficient (Arbuckle 1996) ${ }^{1}$. Further discussions and applications for this model may be found, for example, in Bollen and Curran (2006), Browne and Du Toit (1991), Curran and Muthén (1999), Duncan et al. (2006), McArdle (1986, 1988, 1989, 1991, in press), McArdle and Epstein (1987), Meredith and Tisak (1990), Muthén (1991, 1996), Muthén and Curran (1997), Reinecke (2005), Reinecke and Seddig (in press) and Willett and Sayer (1994). In the next section we turn to the description of our data to test the development of the different elements of GFE.

\section{Empirical analysis}

\subsection{Data}

Data were drawn from a recent representative panel study of the German adult population aged 16 years and over (see Heitmeyer 2008) between 2002 and 2006. Computer-assisted telephone interviews (CATI) were conducted at four time points, 2002, 2003, 2004 and 2006. 2,722 German residents without any immigration background were interviewed in the summer of $2002.1,383$ respondents ( $51 \%$ of the original sample) were re-interviewed in the summer of 2003. In the summer of 2004,825 of them ( $30 \%$ of the original sample) were re-interviewed. Of these, 551 could be relocated and re-interviewed in the summer

\footnotetext{
${ }^{1}$ Although FIML assumes MAR, this assumption is difficult to prove in panel data and may be violated.
} 
of $2006 .{ }^{2}$ Data were collected to serve as social monitoring for the German society with the goal of finding out how people of different social, religious, and ethnic backgrounds or with different lifestyles are perceived by the majority of Germans and whether and to what extent they are confronted with hostile attitudes.

\subsection{Variables}

Six elements of GFE, anti-Semitism, racism, xenophobia, homophobia, exclusion of homeless people and support for rights of the established were measured, each by two indicators ${ }^{3}$. The indicators used for the six prejudice elements are presented in Table 1. For example, two questions are used to measure anti-Semitism. Respondents are asked to indicate whether they agree with the statements that Jews have too much influence in Germany and that due to their behavior, Jews are also responsible for how they were treated. Respondents indicated their agreement on a four-point response scale from 1 (fully agree) to 4 (fully disagree). All items were recoded so that higher numbers would mean higher enmity.

Table 1 about here

Four sociodemographic variables measured in the sample of 2002 are presented in Table 2 with means and standard deviations. They include the variables place of residence (East/West), receiving the value of 1 if respondent lives in West Germany and

\footnotetext{
${ }^{2}$ Additional representative cross-sectional studies in 2003, 2004 and 2006 were used to control that there were no significant differences in several sociodemographic characteristics between the panel respondents and respondents in the new samples. Christ (2006) shows that panel mortality was not systematic but rather produced missing at random. For further details on the design see Zick, Wolf, Küpper, Davidov, Schmidt and Heitmeyer 2008, Schlueter, Davidov and Schmidt 2006, Gensicke 2003, Gensicke and Geiss 2004, and Christ 2006.

${ }^{3}$ These elements were chosen by the project designers because they mirror important elements of prejudice in German society. However, GFE elements may vary across time, cultures and individuals (see, e.g., Zick et al. 2008, or Küpper and Zick 2010). Islamophobia was excluded from the analysis because the questions used to measure it changed during the panel.
} 
2 if in East Germany; Education (1= no school leaving certificate attained; 2 = lowest secondary education certificate; $3=$ middle secondary education certificate; $4=$ upper secondary education certificate mandatory for university qualification; $5=$ higher education); Age (in years); and political orientation (right/left) receiving the value of 1 if respondent has a left-wing political orientation and 5 if respondent has a right-wing political orientation.

Table 2 about here

\subsection{Descriptive Overview}

Table 1 presents mean values for each indicator of the various elements of GFE across the four panel waves. An examination of the table reveals that a few changes have taken place in the mean level during the time period 2002-2006. However, these changes are not uniform for the different elements of GFE. Some elements display more change than others, and the pattern of change is diverse. In particular, the general scores of racism and xenophobia show little or no change over time with a small increase in the first waves followed by a small decrease. Anti-Semitism displays no change between the first and the second waves, an increase in the third wave and a substantial decrease in the fourth wave. Homophobia and exclusion of homeless people display a marginal increase over the first three waves and a decrease back to their initial level in the fourth wave. Interestingly, the only GFE element which shows a continuous linear increase over time is rights of the established. This element has displayed an ongoing increase over the whole period of data collection between 2002 and 2006. Figure 1 presents the observed changes in each of the GFE elements. 
Figure 1 about here

This descriptive overview observed the total scores of each element of the GFE syndrome. The literature has shown that when one controls for measurement error, results may change, as measurement errors could severely bias mean comparisons of index variables (Bollen 1989). To test whether there was a "real" change in support for rights of the established in Germany during the time-period 2002-2006 as opposed to the other elements of GFE, in the next section we are going to run a second order latent growth curve model while controlling for random and nonrandom measurement errors of the observed indicators.

\subsection{Unconditional Latent Growth Curve Models}

There are different ways to proceed with the statistical analysis for delineating the development of GFE over time. One way would be to model GFE as a second order factor at each time point and run a single LGM model for GFE rather than separate LGM models for each of the six elements of group-focused enmity. The level of the total GFE syndrome in each of the four time points would be 'explained' by an intercept and a slope factor. As a second order factor it would be reflected by its six elements at each time point. These six elements will be modeled as first order factors in the model (see Reinecke 2005). Alternatively, we chose to delineate the development of the GFE elements over time separately. The reason is that we have observed different developmental patterns for the various GFE elements in the previous section. We would like to account for these descriptive findings using an LGM model for each element 
separately. A single LGM model for the whole GFE concept would not allow us to consider such differences in the change pattern over time.

Statistical analyses were performed using the program Amos 17.0 (see Arbuckle 2007) and the full information maximum likelihood (FIML) approach. We restricted the factor loadings between indicators and their respective first order factors (the elements of GFE) and the indicators intercepts to be identical over time. This will guarantee that the meaning of the first order factors does not change over time (this is discussed in the literature as metric invariance) and that the scale is used similarly over time (this is termed in the literature as scalar invariance; see, e.g., Horn and McArdle 1992, Meredith 1993, Steenkamp and Baumgartner 1998, Vandenberg and Lance 2000, Cheung and Rensvold 2002, Harkness, Van de Vijver,and Mohler 2003 (Ch. 3), Billiet and Welkenhuysen-Gybels 2004, De Beuckelaer 2005, McArdle in press). ${ }^{4}$ In other words, we apply a 'top-down' strategy in which we start with a restricted model. If the "time invariant" model does not fit to the data, then we should consider releasing some of the constraints. Furthermore, we are starting with specifying a linear model for each of the GFE elements to find out whether there is a linear increase. We do this by setting the regression coefficients between the slope and the GFE elements at time points 2002, 2003, 2004 and 2006 to be $0,1,2$ and 4, respectively. This corresponds to a 1-year interval between the first three panel waves and a 2-year interval between the third and the fourth panel waves. If this specification is rejected, we adapt one or two of the loadings from the slope to the GFE elements to better correspond to the longitudinal

\footnotetext{
${ }^{4}$ A stricter test which guarantees that the meaning of the constructs is stable over time would require also conducting cognitive pre-tests and the collection of qualitative data. Unfortunately, such data is not available in this survey.
} 
change. ${ }^{5}$ Results reporting the means and variances of the slope and the intercept for each of the six GFE elements, the covariance between the slope and the intercept, the respective regression coefficients between the slope and the GFE elements at time points 2002, 2003, 2004 and 2006 and the global fit measures are presented in Table 3.

\section{Table 3 about here}

Based on the global fit measures which are presented in Table 3, we cannot reject any of the six time invariant LGM models which constrain the factor loadings and the indicator intercepts to be equal over time (Hu and Bentler 1999; Marsh, Hau and Wen 2004). All factor loadings between indicators and the first order constructs are substantial (greater than 0.4) in the four waves. This implies that the indicators measure our theoretical constructs well. Table 3 also presents the trajectories chosen for each of the GFE elements. Now we turn to the other findings presented in Table 3.

As is shown in Table 3, all slopes and intercepts have mean values significantly higher than zero. In other words, purged from measurement errors, group-focused enmity elements start from a level significantly higher than zero and subsequently change over time. As is evident in the table, these means of the intercepts, which represent mean levels of the GFE elements in 2002, are quite different from the index scores presented in Table 1 for 2002. The reason is that in contrast to the means of manifest variables presented in Table 1, the means in Table 3 present estimates of latent variables purged from measurement error. The significant variances of the slope and the intercept imply

\footnotetext{
${ }^{5}$ Alternative strategies would imply considering nonlinear developments with the quadratic growth curve model or different pieces of developments via specification of a piecewise trajectory model (Bollen and Curran 2006; see also McArdle in press). However, with only few time points in the data set, we preferred to adapt the loadings to the change pattern rather than to specify a more complex or a piecewise trajectory model. Furthermore, we tried a quadratic model for several elements of GFE. However, the model did not fit the data for several of them and required various modifications.
} 
that there is variability in the initial level and in the change process of the GFE elements. However, whereas the variance of the intercept of all elements of the GFE with the exception of racism turned out to be significant, this was the case only for the variance of the slopes of xenophobia and homophobia. In other words, whereas the initial level of most GFE elements is very heterogeneous in the German population, the change pattern is not very different across individuals for most GFE elements. If change takes place, it takes quite a similar form across groups.

Furthermore, the change pattern took a different form for the various GFE elements as can be seen on the sixth column of Table 3. In this column, the regression coefficients from the slope to the elements of the GFE in the different time points are displayed. None of them indicates a continuous linear increase over time with one exception, rights of the established. The reason that a nonlinear trajectory was chosen for most of the GFE elements is that this trajectory best describes the descriptive data over time presented in Table 1. This data indicate that these GFE elements increase in the first panel years and decrease later. The coefficients from the slope to the different time points reflect this process (for alternative strategies to model nonlinear processes, see, e.g., Duncan et al. 2006). Racism, xenophobia, anti-Semitism, homophobia and exclusion of homeless people all display some increase followed by some decrease as is evident in the regression coefficients. By way of contrast, rights of the established displays a constant linear increase. The size of increase per year for support of rights of the established is estimated in the mean slope to be .05 . In other words, between 2002 and 2006 they have increased by .05 per year (on a scale of 1 to 4 ). This development is illustrated in Figure 2. Finally, the nonsignificant covariance between the slope and the intercept implies that 
there is no relation between the initial level of GFE and its change for the reference time point 2002.

Figure 2 about here

To explain variability in the intercept and the slope, namely, to provide substantive explanations for the level and change of GFE, it is necessary to include predictors into the model and condition the slope and the intercept onto such predictors. In the next section we turn to the results of the conditional LGM models. Our discussion in the previous section has led us to expect people living in East Germany $(H 1)$, older people $(H 2)$, less educated individuals $(H 3)$ and people politically oriented to the right $(H 4)$ to $(a)$ be more prejudiced and (b) that their prejudice scores increase more rapidly over time. Since we found that only the variances of the slope of xenophobia and homophobia were significant, and that the variance of the intercept of racism was not significant, the following conditional LGM models will focus on the explanation of the slopes and intercepts whose variance was found to be significant.

\subsection{Conditional Latent Growth Curve Models}

To test our hypotheses we conditioned five of the six LGM models of the GFE elements (with the exception of racism whose variances for both the intercept and slope were not significant) on four explanatory variables: place of residence (East or West Germany), age, education and political orientation. The intercept in each of the models and the slopes of xenophobia and homophobia were regressed on these four variables. The results summarizing the effects of these predictors are presented in Table 4.

Table 4 about here 
Table 4 presents the standardized regression coefficients of the effects of East/West, age, education and political orientation on the intercept and the slope of the GFE elements whose variance turned out to be significant in the previous section. Several findings are noteworthy: First, in almost all models, place of residence, age, education and political orientation exert a significant effect in the expected direction on the intercept. Older and less educated individuals with a right-wing political orientation living in East Germany display higher initial levels in each of the GFE elements with one exception; East Germans do not display higher initial levels in support for rights of the established. This finding stands in opposition to the hypothesis that East Germans show higher enmity for all GFE elements. This finding could be explained in light of the fact that the rights of the established refers to discrimination of newcomers. Since many of the East Germans may consider themselves as newcomers (joining West Germany after reunification), they avoid rating this GFE dimension highly in order not to discriminate themselves. Finally, it is also worth noting that even after controlling for the effects of age, education and political orientation, place of residence still has a positive and significant effect on the intercept of the GFE elements. In other words, all other things being equal, people living in the East display higher levels of prejudice in 2002 toward minority groups in Germany irrespective of their education level, age or political orientation.

Now we turn to the effects of the sociodemographic predictors on the slopes of xenophobia and homophobia. Whereas East Germans display higher initial levels in xenophobia and homophobia, there are no marked differences in the change rate of these elements among East and West Germans. People in East and West Germany change their 
attitudes toward foreigners and homosexuals over time in a similar way. While older people display higher initial levels for xenophobia and homophobia, they are more reluctant to change their scores over time as evident in the significant and negative effect of age on the slope of xenophobia and homophobia. Individuals with higher education display not only lower levels of prejudice but also lower rates of change in xenophobia and homophobia as indicated by the negative effect of education on the slopes. Thus, their level of prejudice remains rather stable over time compared with individuals with lower education. . Finally, people with a right-wing political orientation display lower rates of change in xenophobia and higher rates of change in homophobia. In other words, whereas their initial prejudice level toward both of these groups is higher in the German population, their negative attitudes toward homosexuals change more rapidly over time whereas their aversion toward foreigners seems to be more stable. In sum, our hypotheses regarding the effect of sociodemographic characteristics on the level (intercept) of GFE elements were (with one exception) supported by the data. However, for the most part, we did not find support for similar effects on the slopes.

Whereas the multivariate analyses provide insights into whether and how the level and change rate in different dimensions of group-focused enmity differ among various groups in German society, they still do not help us to understand why we find diverse change patterns for different GFE elements. In particular, whereas five of the six elements (racism, xenophobia, anti-Semitism, homophobia and exclusion of homeless people) displayed an increase in the first waves followed by a decrease in the last wave, support for rights of the established displayed a continuous linear increase over the whole period 
of data collection. In light of Allport's (1954) assertion that elements of GFE should display similar developmental patterns, this was a rather surprising finding.

\section{Summary and Discussion}

In this study we followed two main goals. First, we wanted to investigate level and change in six elements of group-focused enmity in Germany over the time period $2002-$ 2006: racism, xenophobia, anti-Semitism, homophobia, exclusion of homeless people and support for rights of the established. Second, we tried to explain variability in the level and change rate of different elements of group-focused enmity among various groups in the German society.

To examine our research questions we utilized unconditional and conditional second order latent growth curve models (LGMs) and full information maximum likelihood (FIML) procedure to deal with panel mortality and the problem of missing values. We used representative panel data of the adult non-immigrant German population collected during the years 2002-2006. The second order LGM models were used to

(1) investigate the development over time of each element of group-focused enmity in Germany during these years (using unconditional LGMs); and

(2) explain variation in the level and change in the GFE elements with the sociodemographic variables place of residence, age, education and political orientation (using conditional LGMs).

We applied a second order LGM for each GFE element separately rather than a single LGM for the whole GFE concept because such a model would have concealed the different developmental patterns for each of its elements. Distinct LGM models for each 
GFE dimension allowed us to examine the change pattern for each element of prejudice separately. Indeed, we found that various GFE elements developed differently over time. Five of them, racism, xenophobia, anti-Semitism, homophobia and exclusion of homeless people displayed an increase followed by a decrease at the end of the panel. At the same time, support for rights of the established displayed a continuous linear increase.

In the conditional LGM models it turned out that older, less educated and right-wing individuals living in the East of Germany display higher initial levels of prejudice. However, East Germans did not differ from their Western counterparts in their level of support for rights of the established. In other words, for most of the GFE dimensions, older, less educated and right-wing individuals living in the East of Germany expressed more negative attitudes as we hypothesized. Since there are in East Germany on average higher proportions of right-wing voters, low-educated and older people than in the West, it is not surprising that prejudice levels are also higher there. However, living in the East had a significant positive effect on the initial level of GFE even after accounting for the other predictors. So, other things being equal, people in East Germany are more prejudiced than people in the West.

The variance of the slope turned out to be significant only for xenophobia and homophobia, thus facilitating the study of their change rate over time. In the present analyses, older and less educated individuals displayed a slower change over time in their xenophobic and homophobic attitudes compared to younger, educated respondents. Furthermore, whereas right-wing respondents displayed a slower change rate over time in their xenophobic attitudes, their homophobic attitudes changed more rapidly over time 
compared to left-wing respondents. Finally, there was no difference in the change rate of xenophobia and homophobia among respondents living in East and West Germany.

Other GFE elements did not display any significant variation in their change rate across respondents. It could well be the case that we could not observe significant variances for the slopes of four of the GFE elements because there were only four response categories for the indicators measuring our GFE components. Had there been more response categories per indicator, we might have observed larger variations in the change rate of the GFE elements among respondents. This would have enabled us to study what determines such variations more closely.

There are several limitations to this study. First, it may well be the case that there are other predictors for the intercept and the slope of prejudice that were not included in the conditional LGM model. Including such additional potential predictors may have created a more differentiated picture of the causes of level and change of group-focused enmity. For example, one such additional predictor could be employment status. According to group threat theory, it is suggested that difficult economic conditions may increase perceptions of threat from immigrants or other minorities which may, in turn, increase negative attitudes toward them (Semyonov, Raijman and Gorodzeisky 2006). However, there has been no empirical evidence that unemployment has an effect on prejudice (see, e.g., Wasmer and Koch 2003) and, therefore, this variable was not included as a predictor. Since we conducted a theory-driven test, we decided to include in the analysis those predictors which we regarded as most plausible according to theory. Future research could examine additional predictors and how they potentially interact with each other in the explanation. 
Although our results are important for the study of group prejudice in Germany and its monitoring, it is important to remember that the change in GFE found here is relatively small and the time period studied is too brief to predict with greater confidence patterns of change in prejudice in the future. The full potential of the LGM method and a meaningful introduction of additional social-psychological variables to explain the level and change of the syndrome can be fulfilled more intensively when there is a longer time period available in the data. Often it is assumed that attitudes toward minorities fluctuate in response to external events, such as terror attacks, and in general are prone to change. Our findings suggest that in Germany, across the four years studied, modest changes do take place. Therefore, an uninterrupted measurement of prejudice in Germany is necessary for the continuous inspection of its level and change and an evaluation of their determinants. 


\section{References}

Adorno, T. W., Frenkel-Brunswik, E., Levinson, D. J., \& Sanford, R. N. (1950). The authoritarian personality. New York: Harper \& Row.

Allison, P. D. (1987). Estimation of linear models with incomplete data. In C. Clogg (Ed.), Sociological methodology 1987 (pp. 71-103). Washington, DC: American Sociological Association.

Allport, G. W. (1954). The nature of prejudice. Cambridge, MA: Perseus Books.

Arbuckle, J. L. (1996). Full information estimation in the presence of missing data. In G. A. Marcoulides \& R. E. Schumacker (Eds.), Advanced structural equation modeling: Issues and techniques (pp. 243-277). Mahwah, NJ: Erlbaum.

Arbuckle, J. L. (2007). Amos 16.0 user's guide. Chicago, IL: SPSS Inc.

Bentler, P. M. (1995). EQS structural equations program manual. Los Angeles, CA: Encino.

Bierly, M. M. (1985). Prejudice toward contemporary outgroups as a generalized attitude. Journal of Applied Social Psychology, 15, 189-199.

Billiet, J., \& Welkenhuysen-Gybels, J. (2004). Assessing cross-national construct equivalence in the ESS: The case of six immigration items. Paper presented at the Sixth International Conference on Social Science Methodology. Recent Developments and Applications in Social Research Methodology. August 17-20, Amsterdam.

Bollen, K. A. (1989). Structural equations with latent variables. New York: Wiley.

Bollen, K. A., \& Curran, P. J. (2006). Latent curve models: A structural equation perspective. Hoboken, NJ: John Wiley \& Sons.

Bratt, C. (2005). The structure of attitudes toward non-Western immigrant groups: 
Second-order factor analysis of attitudes among Norwegian adolescents. Group Processes and Intergroup Relations, 8(4), 447-469.

Browne, M. W., \& Du Toit, S. H. C. (1991). Models for learning data. In L. Collins \& J. Horn (Eds.), Best methods for the analysis of change: Recent advances, unanswered questions, future directions (pp.47-68). Washington, DC: American Psychological Association.

Brown, T. A. (2006). Confirmatory factor analysis for applied research. New York: The Guilford Press.

Byrne, B. M. (2006). Structural equation modeling with EQS: Basic concepts, applications and programming. Mahwah, NJ; London: Erlbaum Associates.

Byrne, B. M. (2010). Structural equation modeling with AMOS: Basic concepts, applications and programming. New York, NY: Routledge.

Cheung, G. W., \& Rensvold, R. B. (2002). Evaluating goodness-of-fit indexes for testing measurement invariance. Structural Equation Modeling, 9, 233-255.

Christ, O. (2006). Systematischer Ausfall im GMF-Panel für die ersten drei Wellen [Systematic loss in the GMF Panel for the first three waves of measurement]. Unpublished manuscript.

Curran, P. J., \& Muthén, B. O. (1999). The application of latent curve analysis to testing developmental theories in intervention research. American Journal of Community Psychology, 27(4), 567-595.

Datenreport (2008). Ein Sozialbericht für die Bundesrepublik Deutschland [A social report for the Federal Republic of Germany]. Herausgegeben vom Statistischen Bundesamt, der Gesellschaft Sozialwissenschaftlicher Infrastruktureinrichtungen und 
dem Wissenschaftszentrum Berlin für Sozialforschung. Bonn: Bundeszentrale für politische Bildung.

De Beuckelaer, A. (2005). Measurement invariance issues in international management research. PhD dissertation. Limburg: Limburgs Universitair Centrum.

Duncan, T. E., Duncan, S. C. \& Strycker, L. A. (2006). An introduction to latent variable growth curve modeling: Concepts, issues, and applications. Mahwah, NJ: Lawrence Erlbaum.

Ekehammar, B., Akrami, N., Gylje, M., \& Zakrisson, I. (2004). What matters most to prejudice: Big five personality, social dominance orientation, or right-wing authoritarianism? European Journal of Personality, 18, 463-482.

Enders, C. K. (2001). The impact of nonnormality on the full information maximumlikelihood estimation for structural equation models with missing data. Psychological Methods, 6, 352-370.

Finkel, S. (1995). Causal analysis with panel data. Thousand Oaks: Sage.

Gensicke, T. (2003). Gruppenbezogene Menschenfeindlichkeit. Methodenbericht zur 2. Panelwelle [Group related enmity. Methodological report from the second panel wave]. München: TNS Infratest.

Gensicke, T., \& Geiss, S. (2004). Gruppenbezogene Menschenfeindlichkeit. Methodenbericht zur 3. Panelwelle [Group related enmity. Methodological report from the third panel wave]. München: TNS Infratest.

Graff, J., \& Schmidt, P. (1982). A general method for decomposition of effects. In K. G. Jöreskog \& H. Wold (Eds.), Systems under indirect observation. Causality, structure and prediction. Part I (pp. 131-148). Amsterdam: North-Holland. 
Guimond, S., Dambrun, M., Michinow, N., \& Durarte, S. (2003). Does social dominance generate prejudice? Integrating individual and contextual determinants of intergroup cognition. Journal of Personality and Social Psychology, 84, 697-721.

Hancock, G. R., Wen-Ling, K., \& Lawrence, F. R. (2001). An illustration of second order latent growth models. Structural Equation Modeling, 8, 470-489.

Harkness, J. A., Van de Vijver, F. J. R., \& Mohler, P. P. (Eds.). (2003). Cross-cultural survey methods. New York, NY: John Wiley.

Heitmeyer, W. (Ed.) (2003). Deutsche Zustände. Folge 2 [German States. Volume 2]. Frankfurt a. M.: Suhrkamp.

Heitmeyer, W. (Ed.) (2008). Deutsche Zustände. Folge 6 [German States. Volume 6]. Frankfurt a. M.: Suhrkamp.

Heyder, A., \& Schmidt, P. (2003). Authoritarianism and ethnocentrism in Germany. Does the system matter? In R. A. Alba, P. Schmidt, \& M. Wasmer (Eds.), Germans and foreigners. Attitudes toward minorities in postunification Germany (pp. 187-210). New York: Palgrave MacMillan.

Horn, J. L., \& McArdle, J. J. (1992). A practical and theoretical guide to measurement invariance in aging research. Experimental Aging Research, 18, 117-144.

Hu, L.,\& Bentler, P. M. (1999). Cutoff criteria for fit indexes in covariance structure analysis: Conventional criteria versus new alternatives. Structural Equation Modeling, $6,1-55$

Jackman, M. R. (1978). General and applied tolerance: Does education increase commitment to integration? American Journal of Political Science, 22, 302-324.

Jackman, M. R., \& Muha, M. J. (1984). Education and intergroup attitudes: Moral 
enlightenment, superficial democratic commitment, or ideological refinement? American Sociological Review, 49, 751-769.

Jöreskog, K., \& Sörbom, D. (2001). Lisrel 8: User's reference guide. Chicago, IL: Scientific Software International.

Kleinke, K., Stemmler, M., Reinecke, J., \& Lösel, F. (in press). Efficient ways to impute incomplete panel data. Advances in Statistical Analysis.

Kogan, N. (1961). Attitudes toward old people: The development of a scale and an examination of correlates. Journal of Abnormal and Social Psychology, 62, 44-54.

Kunovich, R. M. (2004). Social structural position and prejudice: An exploration of cross-national differences in regression slopes. Social Science Research, 33(1), 20-44.

Küpper, B., \& Zick, A. (2010). Religion and prejudice in Europe. New empirical findings. Dossier for the Network of European Foundations - Initiative for religion and democracy in Europe. London: Alliance Publishing Trust.

LeVine, R. A., \& Campbell, D. T. (1972). Ethnocentrism. Theories of conflict, ethnic attitudes, and group behavior. New York: Wiley.

Marsh, A. \& Sahin-Dikmen, M. (2003). 'Discrimination in Europe'. Report for the European Commission - DG for Economic \& Social Affairs.

Marsh, H. W., Hau, K. T., \& Wen, Z. (2004). In search of golden rules: Comment on hypothesis-testing approaches to setting cutoff values for fit indexes and dangers in overgeneralizing Hu and Bentler's (1999) findings. Structural Equation Modeling, $11(3), 320-341$.

McArdle, J. J. (1986). Latent growth within behavior genetic models. Behavioral Genetics, 16, 163-200. 
McArdle, J. J. (1988). Dynamic but structural equation modeling of repeated measures data. In J. R. Nesselroade \& R. B. Cattell (Eds.), Handbook of multivariate experimental psychology (2 ${ }^{\text {nd }}$ ed., pp. 561-614). New York: Plenum Press.

McArdle, J. J. (1989). Structural modeling experiments with multiple growth functions. In P. Ackerman, R. Kanfer, \& R. Cudeck (Eds.), Learning and individual differences: Abilities, motivation and methodology (pp. 71-117). Hillsdale, NJ: Lawrence Erlbaum Associates.

McArdle, J. J. (1991). Structural models of developmental theory in psychology. In P. Van Geert \& L. P. Mos (Eds.), Annals of theoretical psychology (Vol. 7, pp. 139-160). New York: Plenum Press.

McArdle, J. J. (in press). Longitudinal dynamic analyses of cognition in the Health and Retirement Study Panel. Advances in Statistical Analysis.

McArdle, J. J., \& Epstein, D. (1987). Latent growth curves within developmental structural equation models. Child Development, 58, 110-133.

Meredith, W. (1993). Measurement invariance, factor analysis and factorial invariance. Psychometrika, 58, 525-543.

Meredith, W., \& Tisak, J. (1990). Latent curve analysis. Psychometrika, 55, 107-122. Muthén, B. O. (1991). Analysis of longitudinal data using latent variable models with varying parameters. In L. M. Collins \& J. L. Horn (Eds.), Best methods for the analysis of change: Recent advances, unanswered questions, future directions (pp. 117). Washington, DC: APA.

Muthén, B. O. (1996). Latent variable modeling of longitudinal and multilevel data: CSE Technical Report 412. University of California. Los Angeles. 
Muthén, B. O., \& Curran, J. P. (1997). General longitudinal modeling of individual differences in experimental designs: A latent variable framework for analysis and power estimation. Psychological Methods, 2, 371-402.

Muthén, B., Kaplan, D., \& Hollis, M. (1987). On structural equation modeling with data that are not missing completely at random. Psychometrica, 52, 431-462.

Muthén, L. K., \& Muthén, B. O. (1998-2010). Mplus: Statistical analysis with latent variables; User's guide. Los Angeles, CA: Muthén \& Muthén.

Ozaki, T., Kino, H., Yu, J., Han, M.vJ., Kobayashi, N., Ohfuti, M., Ishii, F., Ohwaki, T., Weng, H., Toyoda, M., \& Terakura, K. (2009). User's manual of OpenMX Ver. 3.5. http://www.openmx-square.org/openmx_man3.5/openmx3.5.pdf (04.07.2010)

Rao, C. R. (1958). Some statistical methods for the comparison of growth curves. Biometrics, 14, 1-17.

Reinecke, J. (2005). Strukturgleichungsmodelle in den Sozialwissenschaften [Structural equation modeling in the social sciences]. München: Oldenbourg.

Reinecke, J., \& Seddig, D. (in press). Growth mixture models in longitudinal research. Advances in Statistical Analysis.

Schafer, J. L., \& Graham, J. W. (2002). Missing data: Our view of the state of the art. Psychological Methods, 7(2), 147-177.

Schlüter, E., Davidov, E., \& Schmidt, P. (2006). The dynamics of authoritarianism and anomia: Applying autoregressive cross-lagged and latent growth models to a threewave panel study. In: van Montfort, K., Oud, H., \& Satorra, A. (Eds.), Recent developments in structural equation modeling: Theory and application (pp. 263-293). Dordrecht: Kluwer Academic Publishers. 
Semyonov, M., Raijman, R., \& Gorodzeisky, A. (2006). The rise of anti-foreigner sentiment in European societies, 1988-2000. American Sociological Review, 71, 426449.

Steenkamp, J.-B., \& Baumgartner, H. (1998). Assessing Measurement invariance in cross national consumer research. Journal of Consumer Research, 25, 78-90.

Sumner, W. G. (1906). Folkways. A study of the sociological importance of usages, manners, customs, mores and morals. Boston, MA: Ginn.

Tucker, L. R. (1958). Determination of parameters of a functional relation by factor analysis. Psychometrika, 23, 19-23.

Vandenberg, R. J., \& Lance, C. E. (2000). A review and synthesis of the measurement invariance literature: Suggestions, practices and recommendations for organizational research. Organizational Research Methods, 3, 4-69.

Wasmer, M., \& Koch, A. (2003). Foreigners as second class citizens? Attitudes toward equal civil rights for non-Germans. In Alba, R., Schmidt, P., \& Wasmer, M. (Eds.), Germans or foreigners? Attitudes toward ethnic minorities in post-reunification Germany (pp. 95-118). New York: Palgrave.

Whitley, B. E. Jr. (1999). Right-wing authoritarianism, social dominance orientation, and prejudice. Journal of Personality and Social Psychology, 77, 126-134.

Willett, J. B., \& Sayer, A. G. (1994). Using covariance structure analysis to detect correlates and predictors of change. Psychological Bulletin, 116, 363-381.

Zick, A., Wolf, C., Küpper, B., Davidov, E., Schmidt, P., \& Heitmeyer, W. (2008). The syndrome of group-focused enmity: The interrelation of prejudices tested with multiple cross-sectional and panel data. Journal of Social Issues, 64(2), 363-383. 
Table 1: GFE elements, item names and question wording, means and standard deviations (in parentheses) by panel wave (2002, 2003, 2004 and 2006)

\begin{tabular}{|c|c|c|c|c|c|c|}
\hline GFE element & Items & Item Wording & $\begin{array}{c}\text { Means } \\
\text { (standard } \\
\text { dev.) } \\
1^{\text {st }} \text { wave } 2002 \\
(\mathrm{~N}=\mathbf{2 , 7 2 2})\end{array}$ & $\begin{array}{c}\text { Means } \\
\text { (standard } \\
\text { dev.) } \\
2^{\text {nd }} \text { wave } 2003 \\
(N=1,383)\end{array}$ & $\begin{array}{c}\text { Means } \\
\text { (standard } \\
\text { dev.) } \\
3^{\text {rd }} \text { wave } 2004 \\
(\mathrm{~N}=825)\end{array}$ & $\begin{array}{c}\text { Means } \\
\text { (standard } \\
\text { dev.) } \\
4^{\text {th }} \text { wave } 2006 \\
(\mathrm{~N}=551)\end{array}$ \\
\hline \multirow[t]{3}{*}{ Racism } & & Racism score & 1.70 & 1.73 & 1.70 & 1,66 \\
\hline & R1 & $\begin{array}{l}\text { "Aussiedler" should be better treated } \\
\text { than foreigners, because they are of } \\
\text { German origin. }\end{array}$ & $\begin{array}{l}1.80 \\
(0.86)\end{array}$ & $\begin{array}{l}1.81 \\
(0.80)\end{array}$ & $\begin{array}{l}1.83 \\
(0.79)\end{array}$ & $\begin{array}{r}1.80 \\
(0.78)\end{array}$ \\
\hline & $\mathrm{R} 2$ & $\begin{array}{l}\text { White people have the right to have } \\
\text { a leading position in the world. }\end{array}$ & $\begin{array}{l}1.60 \\
(0.82)\end{array}$ & $\begin{array}{l}1.64 \\
(0.80)\end{array}$ & $\begin{array}{l}1.56 \\
(0.77)\end{array}$ & $\begin{array}{l}1.51 \\
(0.75)\end{array}$ \\
\hline \multirow[t]{3}{*}{ Xenophobia } & & Xenophobia score & 2.29 & 2.32 & 2.36 & 2.32 \\
\hline & F1 & $\begin{array}{l}\text { There are too many foreigners in } \\
\text { Germany. }\end{array}$ & $\begin{array}{l}2.52 \\
(1.04)\end{array}$ & $\begin{array}{l}2.51 \\
(1.00)\end{array}$ & $\begin{array}{l}2.56 \\
(1.00)\end{array}$ & $\begin{array}{l}2.58 \\
(0.99)\end{array}$ \\
\hline & F2 & $\begin{array}{l}\text { If working places become scarce, } \\
\text { foreigners living in Germany should } \\
\text { be sent back to their home country. }\end{array}$ & $\begin{array}{l}2.05 \\
(0.93)\end{array}$ & $\begin{array}{l}2.12 \\
(0.91)\end{array}$ & $\begin{array}{l}2.16 \\
(0.90)\end{array}$ & $\begin{array}{l}2.06 \\
(0.88)\end{array}$ \\
\hline \multirow[t]{3}{*}{ Anti-Semitism } & & Anti-Semitism score & 1.72 & 1.73 & 1.81 & 1.61 \\
\hline & A1 & $\begin{array}{l}\text { Jews have too much influence in } \\
\text { Germany. }\end{array}$ & $\begin{array}{l}1.81 \\
(0.84)\end{array}$ & $\begin{array}{l}1.81 \\
(0.84)\end{array}$ & $\begin{array}{c}1.91 \\
(0.83)\end{array}$ & $\begin{array}{c}1.73 \\
(0.84)\end{array}$ \\
\hline & A2 & $\begin{array}{l}\text { Due to their behavior, Jews are also } \\
\text { responsible for how they were } \\
\text { treated. }\end{array}$ & $\begin{array}{l}1.63 \\
(0.80)\end{array}$ & $\begin{array}{l}1.65 \\
(0.80)\end{array}$ & $\begin{array}{l}1.70 \\
(0.80)\end{array}$ & $\begin{array}{l}1.48 \\
(0.69)\end{array}$ \\
\hline \multirow[t]{3}{*}{ Homophobia } & & Homophobia score & 2.05 & 2.11 & 2.16 & 2.05 \\
\hline & $\mathrm{H} 1$ & $\begin{array}{l}\text { Marriage between two women or } \\
\text { two men should be allowed. }\end{array}$ & $\begin{array}{l}2.06 \\
(1.15)\end{array}$ & $\begin{array}{l}2.07 \\
(1.10)\end{array}$ & $\begin{array}{l}2.13 \\
(1.08)\end{array}$ & $\begin{array}{l}2.01 \\
(1.08)\end{array}$ \\
\hline & $\mathrm{H} 2$ & $\begin{array}{l}\text { It is disgusting when homosexuals } \\
\text { kiss in public. }\end{array}$ & $\begin{array}{l}2.03 \\
(1.09)\end{array}$ & $\begin{array}{l}2.14 \\
(1.09)\end{array}$ & $\begin{array}{l}2.19 \\
(1.06)\end{array}$ & $\begin{array}{c}2.09 \\
(1.03)\end{array}$ \\
\hline Exclusion of & & Exclusion of homeless people score & 2.30 & 2.33 & 2.37 & 2.28 \\
\hline
\end{tabular}




\begin{tabular}{|c|c|c|c|c|c|c|}
\hline \multirow[t]{2}{*}{ homeless people } & O1 & $\begin{array}{l}\text { Homeless people should be removed } \\
\text { from pedestrian zones. }\end{array}$ & $\begin{array}{l}2.24 \\
(0.98)\end{array}$ & $\begin{array}{r}2.28 \\
(0.94)\end{array}$ & $\begin{array}{l}2.32 \\
(0.89)\end{array}$ & $\begin{array}{l}2.24 \\
(0.89)\end{array}$ \\
\hline & $\mathrm{O} 2$ & $\begin{array}{l}\text { Homeless people in the towns are } \\
\text { unpleasant. }\end{array}$ & $\begin{array}{r}2.36 \\
(0.91)\end{array}$ & $\begin{array}{l}2.37 \\
(0.90)\end{array}$ & $\begin{array}{r}2.41 \\
(0.86)\end{array}$ & $\begin{array}{r}2.31 \\
(0.86)\end{array}$ \\
\hline \multirow{3}{*}{$\begin{array}{l}\text { Rights of the } \\
\text { established }\end{array}$} & & Rights of the established score & 2.33 & 2.39 & 2.44 & 2.51 \\
\hline & E1 & $\begin{array}{l}\text { When one is a "newcomer", s/he } \\
\text { should be satisfied with less. }\end{array}$ & $\begin{array}{r}2.55 \\
(0.98)\end{array}$ & $\begin{array}{r}2.62 \\
(0.92)\end{array}$ & $\begin{array}{l}2.67 \\
(0.87)\end{array}$ & $\begin{array}{l}2.72 \\
(0.92)\end{array}$ \\
\hline & E2 & $\begin{array}{l}\text { One who has always lived here } \\
\text { should have more rights than those } \\
\text { who came later. }\end{array}$ & $\begin{array}{l}2.11 \\
(1.02)\end{array}$ & $\begin{array}{l}2.15 \\
(0.98)\end{array}$ & $\begin{array}{l}2.20 \\
(0.94)\end{array}$ & $\begin{array}{l}2.31 \\
(0.98)\end{array}$ \\
\hline
\end{tabular}


Table 2: Measurement scale, means and standard deviations of sociodemographic variables (measured in 2002):

\begin{tabular}{|l|l|l|l|}
\hline Variable & Scale & Mean & Standard deviation \\
\hline East/West & $1=$ West Germany; 2 = East Germany & 1.39 & 0.49 \\
\hline Age & In years & 47.94 & 15.01 \\
\hline Education & $\begin{array}{l}1=\text { no school leaving certificate attained; } \\
2=\text { lowest secondary education certificate; } \\
3=\text { middle secondary education certificate; } \\
4=\text { upper secondary education certificate } \\
\text { mandatory for university qualification; }\end{array}$ & 3.27 & 1.10 \\
& $5=$ higher education & & \\
\hline Right/left & $1=$ left-wing; 5 =right-wing & 2.76 & 0.79 \\
\hline
\end{tabular}


Table 3: Means and variances of the slope and the intercept, their covariance and regression coefficients from the slope to each of the GFE elements (unstandardized estimates)

\begin{tabular}{|c|c|c|c|c|c|c|}
\hline GFE element & & Means & Variance & $\begin{array}{l}\text { Cov. between slope and } \\
\text { intercept (2002 is reference } \\
\text { time point) }\end{array}$ & $\begin{array}{l}\text { Regression coeff. from the } \\
\text { intercept and slope to the GFE } \\
\text { element }(2002,2003,2004 \text { and } \\
2006)\end{array}$ & Global fit measures $^{\mathrm{a}}$ \\
\hline \multirow[t]{2}{*}{ Racism } & Intercept & $1.58 *$ & N.S. & \multirow[t]{2}{*}{ N.S. } & $1,1,1,1$ & \multirow{2}{*}{$\begin{array}{l}\text { CFI }=.991 ; \text { RMSEA }=.04 ; \\
\text { Pclose }=.90\end{array}$} \\
\hline & Slope & $.06^{*}$ & N.S. & & $0,1,0,-1$ & \\
\hline \multirow[t]{2}{*}{ Xenophobia } & Intercept & $2.05 *$ & $.76^{*}$ & \multirow[t]{2}{*}{ N.S. } & $1,1,1,1$ & \multirow{2}{*}{$\begin{array}{l}\mathrm{CFI}=.995 ; \mathrm{RMSEA}=.04 \\
\text { Pclose }=.93\end{array}$} \\
\hline & Slope & $.05^{*}$ & $.02 *$ & & $0,1,2,1$ & \\
\hline \multirow[t]{2}{*}{ Anti-Semitism } & Intercept & $1.61^{*}$ & $.36^{*}$ & \multirow[t]{2}{*}{ N.S. } & $1,1,1,1$ & \multirow{2}{*}{$\begin{array}{l}\text { CFI }=.992 ; \text { RMSEA }=.05 ; \\
\text { Pclose }=.50\end{array}$} \\
\hline & Slope & $.12^{*}$ & N.S. & & $0,0,1,-1$ & \\
\hline \multirow[t]{2}{*}{ Homophobia } & Intercept & $2.07^{*}$ & $.77^{*}$ & \multirow[t]{2}{*}{$-.01^{\dagger}$} & $1,1,1,1$ & \multirow{2}{*}{$\begin{array}{l}\text { CFI }=.995 ; \text { RMSEA }=.05 \\
\text { Pclose }=.63\end{array}$} \\
\hline & Slope & $.06^{*}$ & $.04 *$ & & $0,1,2,0$ & \\
\hline \multirow{2}{*}{$\begin{array}{l}\text { Exclusion of } \\
\text { homeless people }\end{array}$} & Intercept & $2.33 *$ & $.31 *$ & \multirow[t]{2}{*}{ N.S. } & $1,1,1,1$ & \multirow{2}{*}{$\begin{array}{l}\text { CFI }=.999 ; \text { RMSEA }=.01 \\
\text { Pclose }=1.00\end{array}$} \\
\hline & Slope & $.04 *$ & N.S. & & $0,1,2,0$ & \\
\hline \multirow{2}{*}{$\begin{array}{l}\text { Rights of the } \\
\text { established }\end{array}$} & Intercept & $2.11^{*}$ & $.38^{*}$ & \multirow[t]{2}{*}{ N.S. } & $1,1,1,1$ & \multirow{2}{*}{$\begin{array}{l}\text { CFI }=0.995 ; \text { RMSEA }=.03 ; \\
\text { Pclose }=1.00\end{array}$} \\
\hline & Slope & $.05^{*}$ & N.S. & & $0,1,2,4$ & \\
\hline
\end{tabular}

${ }^{a} \mathrm{CFI}=$ comparative fit index; RMSEA = root mean square error of approximation; Pclose = probability of close fit

$* \mathrm{P}<0.05 ;{ }^{\dagger} \mathrm{P}<0.1 ; \mathrm{N} . \mathrm{S} .=$ not significant 
Table 4: Effects of place of residence (East or West Germany), age, education and political orientation on the change process (intercept and slope) of GFE (standardized coefficients)

\begin{tabular}{|l|c|c|c|c|c|c|c|}
\hline & \multicolumn{2}{|c|}{ Xenophobia } & Anti-Semitism & \multicolumn{2}{|c|}{ Homophobia } & $\begin{array}{c}\text { Exclusion of } \\
\text { homeless people }\end{array}$ & $\begin{array}{c}\text { Rights of the } \\
\text { established }\end{array}$ \\
\hline & Int. & Slope & Int. & Int. & Slope & Int. & Int. \\
\hline East/West & $.22^{*}$ & N.S. & $.06^{*}$ & $.13^{*}$ & N.S. & $.24^{*}$ & N.S. \\
\hline Age & $.05^{*}$ & $-.26^{*}$ & $.17^{*}$ & $.44^{*}$ & $-.10^{*}$ & $.07^{*}$ & $.10^{*}$ \\
\hline Education & $-.18^{*}$ & $-.47^{*}$ & $-.20^{*}$ & $-.10^{*}$ & $-.09^{*}$ & $-.12^{*}$ & $-.30^{*}$ \\
\hline Right/left & $.19^{*}$ & $-.12^{*}$ & $.27^{*}$ & $.26^{*}$ & $.06^{*}$ & $.18^{*}$ & $.26^{*}$ \\
& & & & & & & \\
\hline
\end{tabular}

$* \mathrm{P}<.05$ 
Figure 1: Development of the observed scores of the GFE elements

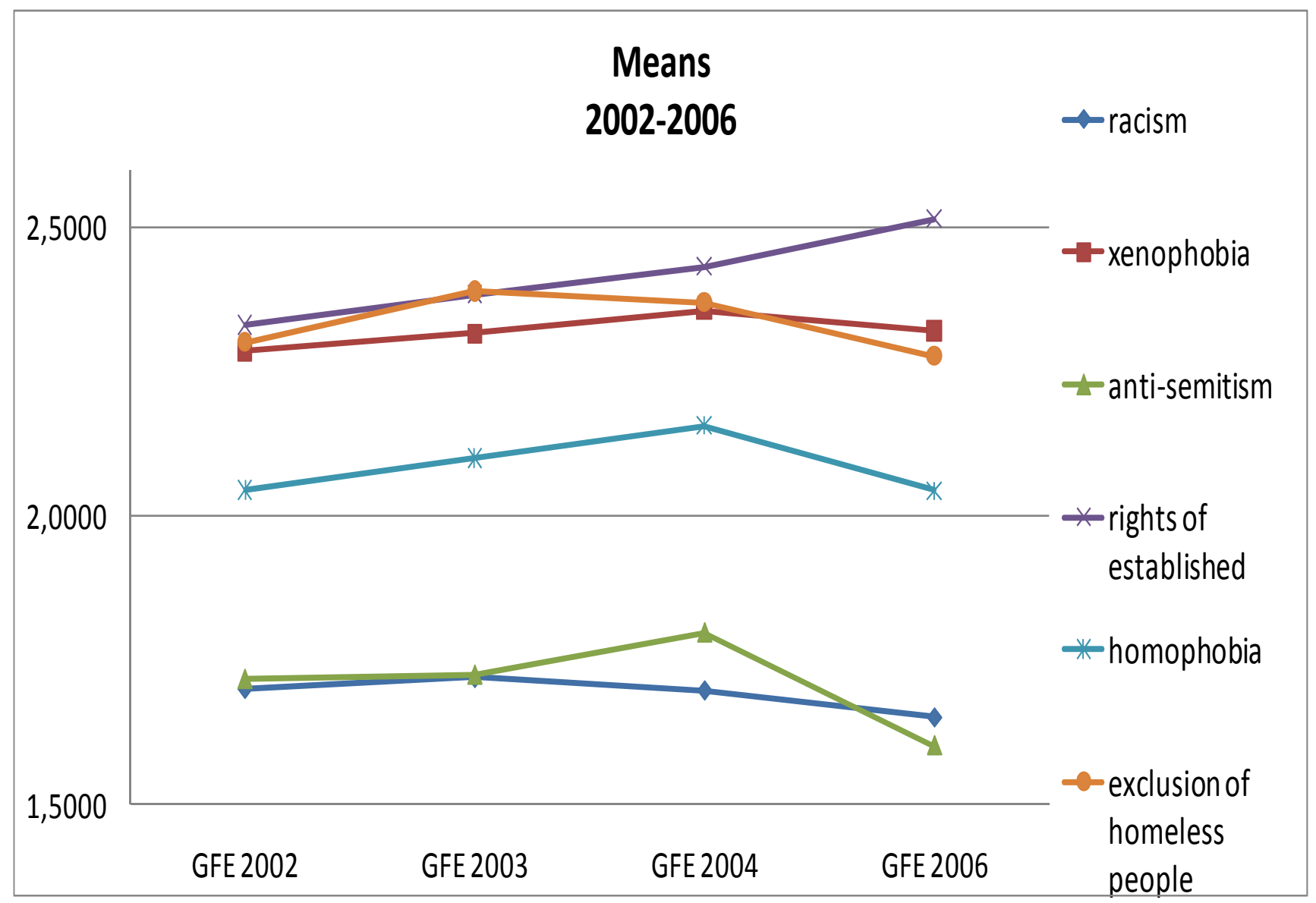


Figure 2: Expected change in the latent variable support for rights of the established

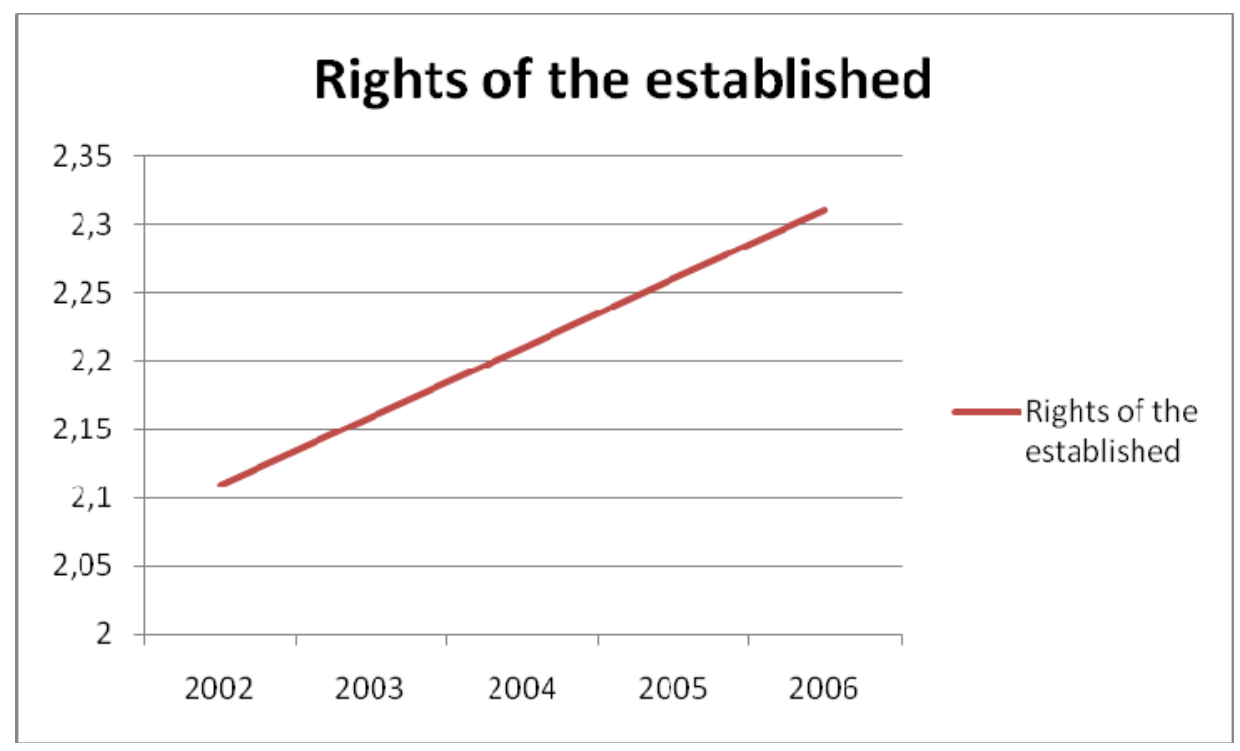

